Check for updates

Cite this: RSC Adv., 2018, 8, 23963

\title{
Silica based inorganic-organic hybrid materials for the adsorptive removal of chromium
}

\author{
Sana Nayab, $\uparrow^{\mathrm{ab}}$ Humaira Baig, $\uparrow^{\mathrm{ac}}$ Abdul Ghaffar, ${ }^{\mathrm{c}}$ Eylül Tuncel, ${ }^{d}$ Zehra Oluz, ${ }^{d}$ \\ Hatice Duran (D) and Basit Yameen (D) *a
}

We employed polymer functionalized silica gel as an adsorbent for the removal of $\mathrm{Cr}(\mathrm{VI})$ from water. The chains of 2-aminoethyl methacrylate hydrochloride (AEMA. $\mathrm{HCl}$ ) polymer were grown from the surface of silica gel via surface-initiated conventional radical polymerization and the resulting hybrid material exhibited high affinity for chromium(vi). To investigate the adsorption behavior of $\mathrm{Cr}(\mathrm{VI})$ on diverse polymer based hybrid materials, the removal capacity of (SG-AEMH) was compared with our previously reported branched polyamine functionalized mesoporous silica (MS-PEI). The adsorption capacities of polymer based materials were also compared with their respective monolayer based platforms comprising a 3-aminopropyltriethoxysilane (APTES) functionalized silica gel (SG-APTES) and mesoporous silica (MS-APTES). The polymer based systems showed excellent $\mathrm{Cr}(\mathrm{vI})$ adsorption efficiencies compared to monolayer counterparts. The structural characteristics and surface modification of these adsorbents were examined by Fourier transform infrared spectroscopy (FTIR), transmission electron microscopy (TEM), X-ray photoelectron spectroscopy (XPS), and thermogravimetric analysis (TGA). The experimental data were analyzed using the Langmuir and Freundlich models. Correlation coefficients were determined by analyzing each isotherm. The kinetic data of adsorption reactions were described by pseudo-firstorder and pseudo-second-order equations. Thermodynamic parameters, i.e., change in the free energy $\left(\Delta G^{\circ}\right)$, the enthalpy $\left(\Delta H^{\circ}\right)$, and the entropy $\left(\Delta S^{\circ}\right)$, were also evaluated. The synthesized hybrid materials exhibited a high adsorption capacity for chromium ions. Furthermore, they could be regenerated and recycled effectively.

Received 17th May 2018

Accepted 21st June 2018

DOI: $10.1039 /$ c8ra04209h

rsc.li/rsc-advances
Environmental pollution has become one of the most severe problems, which is harmful to human health and ecological systems. According to recent reports, heavy metals have been considered as the most chronic and acute contaminants globally. ${ }^{1,2}$ Various industries such as printed board manufacturing, semiconductor manufacturing, electroplating, leather tanning, mining, steel making, textile dyes and pigments are the major sources of aquatic pollution. Industrial effluent contains different harmful heavy metals such as chromium, copper, lead, mercury. ${ }^{3}$ Chromium is considered highly alarming for human, animals and plants life. In wastewater, chromium exists in two stable states i.e., $\mathrm{Cr}(\mathrm{vI})$ and $\mathrm{Cr}(\mathrm{III})$. $\mathrm{Cr}(\mathrm{vI})$ is more lethal due to its solubility within almost the whole $\mathrm{pH}$ range and greater

\footnotetext{
${ }^{a}$ Department of Chemistry and Chemical Engineering, SBA School of Science and Engineering, Lahore University of Management Sciences (LUMS), Lahore-54792, Pakistan.E-mail: basit.yameen@lums.edu.pk

${ }^{b}$ Department of Chemistry, Lahore College for Women University (LCWU), Jail Road, Lahore, Pakistan

'Department of Chemistry, University of Engineering and Technology (UET), Lahore, Pakistan

${ }^{d}$ Department of Materials Science \& Nanotechnology Engineering, TOBB University of Economics and Technology, Sögütözü Cad. 43, 06560 Ankara, Turkey

$\dagger$ S. N. and H. B. contributed equally to this work.
}

mobility in the waterbed. ${ }^{4}$ Various methods such as chemical precipitation, membrane filtration, ion exchange, electrochemical processes, chemical coagulation and adsorption have been utilized to remove heavy metals from wastewater. ${ }^{5}$ Among these methods, adsorption is known to be the most efficient method. A large number of natural and synthetic materials have been used for the adsorption-based removal of heavy metals from wastewater. ${ }^{6-9}$ These materials include zeolites, clays, biosorbents, resins, activated carbon magnetic particles and silica. Simple and low cost adsorbents have been synthesized by several researchers for an effective removal of heavy metals including $\mathrm{Cr}(\mathrm{vi})$ even at low concentration. ${ }^{10-17} \mathrm{Li}$ et al., demonstrated the preparation of chitosan nanofibers with an average diameter of $75 \mathrm{~nm}$ and cross linked with glutaraldehyde for the removal of $\mathrm{Cr}(\mathrm{vi}){ }^{18}$ Aboutorabi et al., employed TMU-30 based metal-organic framework (MOF) containing isonicotinate $\mathrm{N}$-oxide as adsorptive sites for the adsorption of $\mathrm{Cr}(\mathrm{vi})$ from aqueous solution..$^{19}$ Recently, Dong et al., prepared the ionic liquid functionalized cellulose (ILFC) through the grafting of glycidyl methacrylate onto cellulose microsphere followed by reaction with ionic liquid 1-aminopropyl-3-methyl imidazolium nitrate for the adsorptive removal of $\mathrm{Cr}(\mathrm{vI}) .{ }^{20}$ Table 1 gives 
Table 1 Comparison of adsorption capacities of different adsorbents for $\mathrm{Cr}(\mathrm{VI})$ removal

\begin{tabular}{|c|c|c|c|c|c|}
\hline $\begin{array}{l}\text { Sr. } \\
\text { no }\end{array}$ & Adsorbents & $\begin{array}{l}\text { Adsorption } \\
\text { capacity } \\
q_{\max }\left(\mathrm{mg} \mathrm{g}^{-1}\right)\end{array}$ & $\begin{array}{l}\text { Time } \\
(\min )\end{array}$ & $\mathrm{pH}$ & References \\
\hline 1 & Carbon/boehmite (AlOOH) composite & 25.6 & 360 & 2.0 & 51 \\
\hline 2 & Titanium oxide-Ag composite & 25.7 & 720 & 2.0 & 52 \\
\hline 3 & Polydopamine coated maghemite NPS (MNP@PDA) & 38.6 & 240 & 3.0 & 53 \\
\hline 4 & $\mathrm{Fe}_{3} \mathrm{O}_{4} @ \mathrm{NiO}$ nanocomposite & 6.9 & 40 & $5-10$ & 54 \\
\hline 5 & $\mathrm{MnFe}_{2} \mathrm{O}_{4} @ \mathrm{SiO}_{2}-\mathrm{CTAB}$ & 25.0 & 30 & 3.0 & 55 \\
\hline 6 & $\mathrm{ZnO} /$ biochar & 43.5 & 120 & $\begin{array}{l}\text { Natural } \\
\mathrm{pH}\end{array}$ & 56 \\
\hline 7 & $\gamma$-AlOOH/PVA granules & 35.9 & 200 & 5.5 & 57 \\
\hline 8 & Yarrowia lipolytica & 5.2 & 120 & 1.0 & 58 \\
\hline 9 & $\begin{array}{l}\beta \text {-Cyclodextrin ionic liquid polyurethane modified magnetic NPs }\left(\mathrm{Fe}_{3} \mathrm{O}_{4} \text {-CDI-IL }\right. \\
\text { MNPs) }\end{array}$ & 2.6 & 180 & 3.0 & 59 \\
\hline 10 & Blends of henna with chitosan microparticles & 17.4 & 66.21 & 3.8 & 60 \\
\hline 11 & Silver-triazolate MOF & 37.0 & 240 & 6 & 61 \\
\hline 12 & $p$-Toluidine formaldehyde resin (PTFR) on silica & 43.5 & 300 & 1.0 & 62 \\
\hline 13 & SG-AEMH & 63.3 & 30 & 4.0 & $\begin{array}{l}\text { Current } \\
\text { study }\end{array}$ \\
\hline 14 & MS-PEI & 50.26 & 30 & 4.0 & $\begin{array}{l}\text { Current } \\
\text { study }\end{array}$ \\
\hline
\end{tabular}

a simple comparison of the adsorption ability of different adsorbent materials for the adsorption of $\mathrm{Cr}(\mathrm{vI})$.

Silica based porous materials are considered as promising adsorbents for water remediation due to their high surface area, well defined tunable pore size and high adsorption capacity. ${ }^{21,22}$ Owing to their economic feasibility, high thermal and mechanical stabilities, they can be utilized as inorganic solid matrixes in the inorganic-organic hybrid materials. ${ }^{23,24}$ Several researchers have contributed in the development of functionalized silica based adsorbents for the removal of heavy metals. ${ }^{25-31}$ Fan et al., prepared the Schiff base functionalized $\mathrm{Pb}(\mathrm{II})$ imprinted silica-supported organic-inorganic hybrid adsorbent for the selective removal of $\mathrm{Pb}(\mathrm{II})$ from aqueous solution. ${ }^{32}$ Radi et al., reported the synthesis of chelate $\beta$ ketoenol furan functionalized silica particles (SiNFn) for the selective adsorption of $\mathrm{Cd}(\mathrm{II}){ }^{33}$ More Recently, Qihui et al., demonstrated the fabrication of thiol functionalized silica microspheres doped with CdTe quantum dots (CQDSMs) for the efficient adsorption of $\mathrm{Ag}^{+} \cdot{ }^{34}$ The surface of silica can be tailored with different functional groups to enhance their selectivity towards specific pollutants. ${ }^{35,36}$ Modification can be achieved via post-synthesis grafting and co-condensation. ${ }^{37}$ Post-synthesis grafting offers a facile avenue to controlling surface properties of materials and facilitates the functionalization of the internal pores of porous materials, ultimately helping in developing material with optimized bulk and interfacial properties. ${ }^{38}$ Numerous organic functional groups such as amine, thiol, carboxylate, alkyl chloride, and aromatic functional groups have been incorporated through post-synthesis grafting strategy. ${ }^{\mathbf{3 9 - 4 4}}$ In case of silica based materials, the silanol groups present on the surface assist the covalent introduction of a wide range of functional groups, which act as stable and efficient chelating moieties towards a variety of metal ions. The excellent metal adsorption property of these functionalized silica materials are attributed to the presence of electron donor heteroatoms such as $\mathrm{O}, \mathrm{S}$ and $\mathrm{N}$ in the incorporated functional groups. ${ }^{45,46}$ The surface functionalization can be either monolayer or polymer based. The polymer based surface functionalization results in a higher surface functional group density that ultimately improves the absorption capacity of the functionalized material. Despite obvious advantages of the polymer based surface

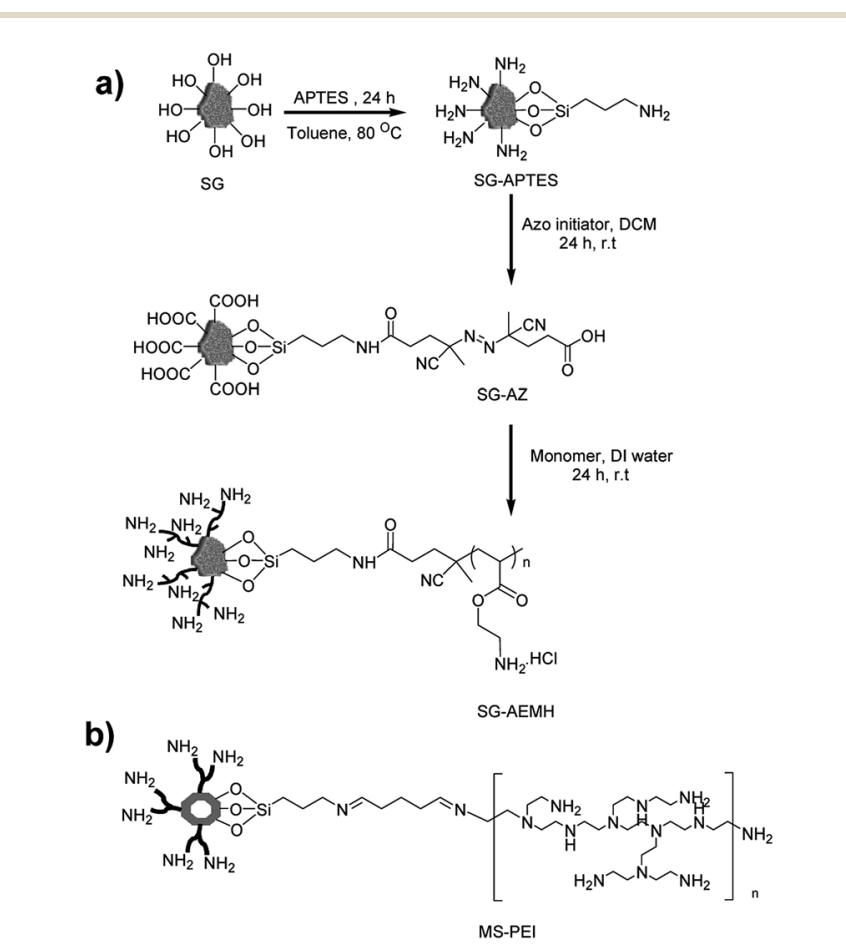

Scheme 1 Schematic illustration of (a) synthesis of APTES based monolayer (SG-APTES) and AEMH based polymer functionalized silica gel (SG-AEMH), (b) polyamine functionalized mesoporous silica (MSPEI). 
functionalization, majority of the efforts in the field of developing materials for water remediation have been focused on monolayer based surface functionalizations.

Herein, we demonstrated the potential of polymer functionalized silica based inorganic-organic hybrid materials for $\mathrm{Cr}(\mathrm{vI})$ adsorption (Scheme 1). The chains of 2-aminoethyl methacrylate hydrochloride were grafted on the surface of silica gel via surface-initiated conventional radical polymerization (SIcRP) approach. We have also compared the adsorption capacity of SG-AEMH with polyamine functionalized MCM-41 mesoporous silica (MS-PEI). ${ }^{47}$ The APTES derived monolayer based amine functionalized silica gel (SG-APTES) and mesoporous silica (MS-APTES) were also examined and compared with polymer grafted silica materials. Our results show that SGAEMH and MS-PEI were more effective for chromium adsorption. Furthermore, the experimental data were fitted to different adsorption models, and the corresponding parameters were determined. In addition, kinetic and thermodynamic analyses were performed to understand the mechanism of the adsorption processes.

\section{Experimental}

\section{Materials and methods}

Silica gel (column chromatography grade, $0.06-0.2 \mathrm{~mm}$ ) and potassium dichromate were purchased from Scharlau, Spain. Hydrochloric acid (37\%) and toluene (99\%) were purchased from Riedel-de Haën, Germany. 2-Aminoethyl methacrylate hydrochloride, Triethylamine (TEA), 1-hexadecyl trimethylammonium bromide (CTAB), aqueous ammonia $\left(\mathrm{NH}_{3}, 35 \%\right)$, tetraethyl orthosilicate (TEOS, 99\%), toluene (99\%), 3-aminopropyltriethoxysilane (APTES, 98\%), glutaraldehyde (GA, 50\% in water), branched polyethyleneimine (PEI, $M_{\mathrm{w}} \sim 25 \mathrm{kDa}$ by LS, $M_{\mathrm{n}}$ $\sim 10$ kDa by GPC, data from Sigma Aldrich), sodium dihydrogen phosphate $\left(\mathrm{NaH}_{2} \mathrm{PO}_{4}, 97 \%\right)$, sodium hydrogen phosphate $\left(\mathrm{Na}_{2} \mathrm{HPO}_{4}, 98 \%\right)$, ethanol (>99\%), acetone and methanol were purchased from Sigma Aldrich, Germany. Acetic acid was obtained from Merck, Germany. TEA was refluxed overnight with calcium hydride, distilled, and stored under a nitrogen atmosphere. 4,4'-Azobis(4-cyanopentanoyl chloride) (ACPC) was synthesized from 4,4'-azobis (4-cyanopentanoic acid) according to a previously reported method. ${ }^{48}$ Toluene was dried using $\mathrm{Na} /$ benzophenone prior to use.

\section{Activation of silica gel surfaces: (SG)}

Silica gel was activated by stirring its suspension in conc. $\mathrm{HCl}$ for $24 \mathrm{~h}$ at ambient temperature. The acid suspension was subsequently diluted with deionized water and activated silica gel was separated by centrifugation ( $4000 \mathrm{rpm}, 10 \mathrm{~min})$. The activated silica gel was washed with deionized water until neutral and dried under vacuum at $90{ }^{\circ} \mathrm{C}$ for overnight.

\section{Synthesis of APTES functionalized silica gel (SG-APTES)}

Amine functionalized silica NPs were prepared by a previously reported method. ${ }^{47}$ Activated silica gel $(4 \mathrm{~g})$ and $10 \%$ APTES solution $(60 \mathrm{~mL})$ were added in dry toluene and refluxed at $80^{\circ} \mathrm{C}$ for $24 \mathrm{~h}$ under inert atmosphere. The reaction mixture was cooled and silica gel was separated by centrifugation at $4000 \mathrm{rpm}$ for $10 \mathrm{~min}$ followed by washing with toluene, acetone and methanol. The APTES functionalized silica gel was dried in a vacuum oven at $70{ }^{\circ} \mathrm{C}$ for overnight.

\section{Surface modification of silica gel with azoinitiator (SG-AZ)}

The surface of silica gel was further modified with azoinitiator according to the previously reported method. ${ }^{49} \mathrm{~A}$ solution of ACPC (4,4-azobis 4-cyanopentanoylchloride) ( 0.5 g) was prepared in $17 \mathrm{~mL}$ of dry dichloromethane, followed by the addition of dry TEA $(216 \mu \mathrm{L})$ under inert atmosphere. This solution was injected over degassed APTES functionalized silica gel (SG-APTES $2 \mathrm{~g}$ ) under nitrogen flow and stirred for $2.5 \mathrm{~h}$ at ambient temperature. The particles were separated by centrifugation (4000 rpm), followed by washing with DCM and ethanol. The particles were stored in refrigerator until further use.

\section{Grafting of poly AEMH $\cdot \mathrm{HCl}$ brushes on the surface of silica gel (SG-AEMH)}

AEMH $\cdot \mathrm{HCl}$ monomer $(2.7 \mathrm{~g})$ was dissolved in $13 \mathrm{~mL}$ deionized water and solution was degassed for $1 \mathrm{~h}$ at room temperature. The monomer solution was transferred to a Schlenk containing already degassed azoinitiator coated silica gel $(0.4 \mathrm{~g})$. The polymerization was carried out under $\mathrm{N}_{2}$ (gas) at $75^{\circ} \mathrm{C}$ for $24 \mathrm{~h}$. Polymer functionalized silica gel was separated by centrifugation (4000 rpm), washed with water and dried in a vacuum oven at ambient temperature for $24 \mathrm{~h}$.

\section{Characterization}

Attenuated total reflection Fourier transform infrared (ATRFTIR) spectra were recorded on Alpha Bruker, spectrometer (Germany). Transmission electron microscopic (TEM) images were obtained on FEI Tecnai G2 F20 instrument with an accelerating voltage of $200 \mathrm{kV}$. Samples were prepared by drop casting two to three drops of particle dispersions in ethanol onto a carbon coated copper TEM grid. X-ray photoelectron spectroscopy (XPS) measurements were carried out using Thermo Scientific K-Alpha. The $\mathrm{Mg} \mathrm{K} \alpha(1253.6 \mathrm{eV}) \mathrm{X}$-ray source was operated at $300 \mathrm{~W}$. Pass energy of $117.40 \mathrm{eV}$ was used for the survey scans. The spectra were recorded using a $60^{\circ}$ take off angle relative to the surface normal. The UV/Vis absorption spectra were recorded using a Shimadzu UV-1800 spectrophotometer. Thermogravimetric measurements were carried out on a TGA Q50 V6.2 Build 187 thermogravimetric analyzer. Samples were heated at $10^{\circ} \mathrm{C} \mathrm{min}{ }^{-1}$ from ambient temperature to $800{ }^{\circ} \mathrm{C}$ under nitrogen flow.

\section{Adsorption studies}

The adsorption studies were carried out by investigating the effect of different $\mathrm{pH}$. The $\mathrm{pH}$ values were adjusted by using $0.1 \mathrm{M} \mathrm{HCl}$ and $0.1 \mathrm{M} \mathrm{NaOH}$. Approximately, $10 \mathrm{mg}$ of adsorbents were shaken at room temperature $(200 \mathrm{rpm})$ with $10 \mathrm{~mL}$ 
aqueous Cr(Iv) solutions of known initial concentration (40 ppm for SG-APTES and SG-AEMH, while $20 \mathrm{ppm}$ for MS-APTES and MS-PEI) at optimized contact time. At the end of the adsorption period, the solutions were centrifuged and the concentration of $\mathrm{Cr}$ (Iv) in the supernatant solutions before and after the adsorption was determined using a calibration curve $\left(\lambda_{\max } 353\right.$ $\mathrm{nm})$. The amount of metal adsorbed at equilibrium $q_{\mathrm{e}}\left(\mathrm{mg} \mathrm{g}^{-1}\right)$ was calculated from the following equation.

$$
q_{\mathrm{e}}=\frac{\left(C_{0}-C_{\mathrm{e}}\right) V}{W}
$$

where $q_{\mathrm{e}}$ is the adsorption capacity $\left(\mathrm{mg} \mathrm{g}^{-1}\right)$ of the adsorbent at equilibrium, $C_{0}$ and $C_{\mathrm{e}}\left(\mathrm{mg} \mathrm{g}^{-1}\right)$ are the initial and equilibrium concentrations of solute, $V$ is the volume of the aqueous solution in liter, and $W$ is the mass in grams of the adsorbent used.

\section{Result and discussion}

The surface functionalization of silica gel with monolayer and polymer was affirmed by FTIR spectroscopic analysis (Fig. 1). The bands at $1054 \mathrm{~cm}^{-1}$ and $791 \mathrm{~cm}^{-1}$ are characteristic of asymmetric and symmetric vibrations of $\mathrm{Si}-\mathrm{O}-\mathrm{Si}$. The surface modification of SG with APTES was confirmed by the appearance of $-\mathrm{NH}_{3}{ }^{+}$bending vibration at $1583 \mathrm{~cm}^{-1}$ followed by the presence of $\mathrm{NH}_{2}$ bending vibration at $1660 \mathrm{~cm}^{-1}$ and $\mathrm{C}-\mathrm{H}\left(\mathrm{CH}_{2}\right)$ stretching vibration at $2867 \mathrm{~cm}^{-1}$ and $2920 \mathrm{~cm}^{-1}$. The $\mathrm{C}=\mathrm{O}$ stretching vibration at $1724 \mathrm{~cm}^{-1}$ and $\mathrm{N}-\mathrm{H}$ stretching vibration of at $3330 \mathrm{~cm}^{-1}$ further supported the immobilization of AEMH on the surface of silica gel. The successful surface modifications were further established by XPS analysis (Fig. 1). The survey scan of SG-APTES showed signals at 143 and $100 \mathrm{eV}$, which correspond to the binding energies of Si 2s and Si 2p orbitals of silicon. The signal for the $\mathrm{C} 1 \mathrm{~s}$ and $\mathrm{O}$ 1s orbitals of the carbon and oxygen contents can be observed at 283 and $532 \mathrm{eV}$. The presence of $\mathrm{N} 1 \mathrm{~s}$ orbital signal at $400 \mathrm{eV}$ in the XPS survey scan supported the amine functionalization of SG. In case of SGAEMA, the XPS survey scan also showed the signal for $\mathrm{Cl} 2 \mathrm{~s}$ $(268 \mathrm{eV})$ and $\mathrm{Cl} 2 \mathrm{p}(198 \mathrm{eV})$, because the monomer used for the
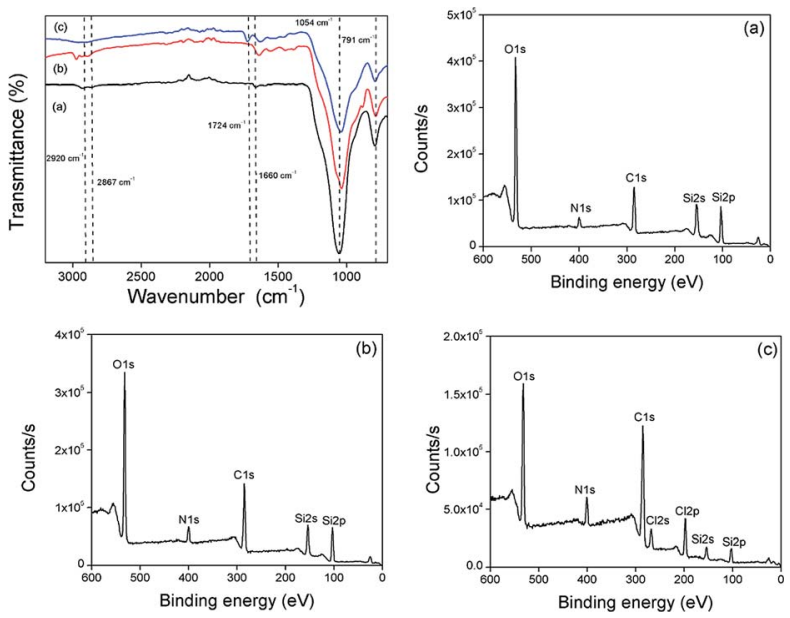

Fig. 1 FTIR spectra of (a) SG-APTES, (b) SG-AZ, (c) SG-AEMH; XPS spectra of (a) SG-APTES, (b) SG-AZ, and (c) SG-AEMH. polymer brush growth was in its hydrochloride form. Thermogravimetric analysis was conducted to evaluate the extent of surface functionalization (Fig. 2). The pristine SG and MS exhibited a total weight loss of $9.92 \%$ and $8.38 \%$ respectively at temperatures up to $800{ }^{\circ} \mathrm{C}$, which was attributed to the weight loss by the removal of silanol groups. In the case of SG-APTES and MS-APTES, the weight loss was $19.55 \%$ and $20.87 \%$, respectively, which was attributed to the decomposition of monolayer of APTES. By grafting the polymer onto the surface of the silica materials, the weight loss rises sharply to $25.90 \%$ for SG-AEMH and $24.32 \%$ for MS-PEI.

In case of silica gel, the evaluation of surface functionalization by TEM (Fig. 3a and $\mathrm{f}$ ) was limited by the large variation in size and relatively thin layer of the surface-immobilized monolayer and polymer. SG forms large clusters size ranges from few micrometres to few hundred nanometres. MS samples, on the other hand, have more regular shapes with narrower size distribution $(\sim 500 \mathrm{~nm})$. The mesopores of MS were also evident in the TEM images. The TEM images of MSPEI revealed a thin layer of PEI coated on the surface of MS.

\section{Effect of pH}

The $\mathrm{pH}$ value of the medium controls the adsorption capacity due to its influence on the ionic forms of the chromium ions in solutions, surface change and protonation degree of functional groups on the adsorbent. $\mathrm{Cr}(\mathrm{vI})$ exists in five main forms in the aqueous solution, including $\mathrm{Cr}_{2} \mathrm{O}_{7}{ }^{2-}, \mathrm{HCr}_{2} \mathrm{O}_{7}{ }^{-}, \mathrm{CrO}_{4}{ }^{2-}$, $\mathrm{HCrO}_{4}{ }^{-}$and $\mathrm{H}_{2} \mathrm{CrO}_{4}$. $\mathrm{CrO}_{4}{ }^{2-}$ is dominant at $\mathrm{pH}>6.0$, while $\mathrm{HCrO}_{4}{ }^{-}$and $\mathrm{Cr}_{2} \mathrm{O}_{7}{ }^{2-}$ exist in equilibrium between $\mathrm{pH} 2$ and $\mathrm{pH}$ 6. Below pH $1, \mathrm{Cr}(\mathrm{vI})$ species are present as $\mathrm{H}_{2} \mathrm{CrO}_{4}$ and $\mathrm{HCr}_{2} \mathrm{O}_{7}{ }^{-}$. To evaluate the adsorption of $\mathrm{Cr}(\mathrm{vI})$ onto the developed adsorbents (SG-APTES, SG-AEMH, MS-APTES, and MS$\mathrm{PEI}$ ) in the $\mathrm{pH}$ range of $\mathbf{2 . 0}-\mathbf{1 2 . 0}, 10 \mathrm{mg}$ of adsorbents were added in $10 \mathrm{~mL} \mathrm{Cr(vi)} \mathrm{solution} \mathrm{(40} \mathrm{ppm} \mathrm{for} \mathrm{SG-APTES} \mathrm{and} \mathrm{SG-}$ AEMH, while 20 ppm for MS-APTES and MS-PEI) and placed in a shaker (180 rpm) at room temperature for $30 \mathrm{~min}$. The $\mathrm{pH}$ of solutions was adjusted by using $0.1 \mathrm{M} \mathrm{HCl}$ and $0.1 \mathrm{M} \mathrm{NaOH}$. The adsorption capacity of all the adsorbents increased as the $\mathrm{pH}$ increased from 2.0 to 4.0 and then decreased as the $\mathrm{pH}$ increased from 4.0 to 12.0 for all the adsorbents. The maximum adsorption capacities of polymer functionalized silica materials were observed at $\mathrm{pH} 4.0$ (93\% for SG-AEMH and 98\% for MSPEI). The increase in the adsorption capacity at low $\mathrm{pH}$ might be attributed to the conversion of $\mathrm{Cr}(\mathrm{vI})$ species into $\mathrm{HCrO}_{4}{ }^{-}$
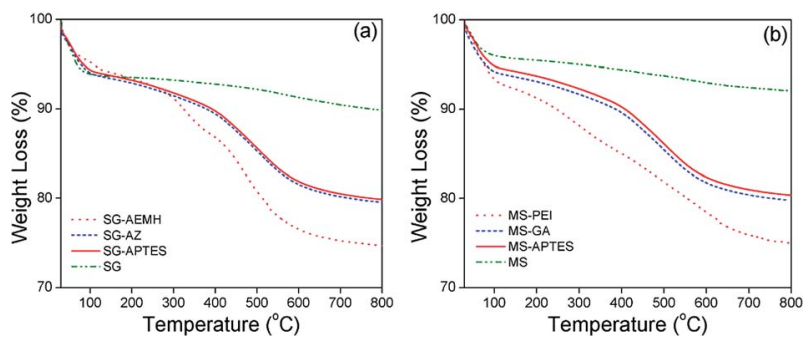

Fig. 2 TGA analysis of (a) as synthesized SG, SG-APTES, SG-AZ, SGAEMH (b) as synthesized MS, MS-APTES, MS-GA, MS-PEI. 

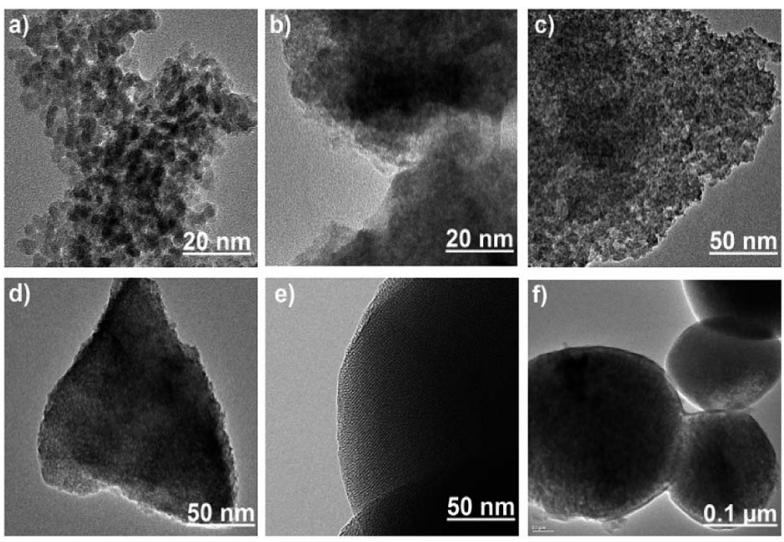

Fig. 3 The HR-TEM images of (a) SG (b) SG-APTES, (c) SG-AZ, (d) SGAEMH, (e) MS-APTES, and (f) MS-PEI.

and $\mathrm{Cr}_{2} \mathrm{O}_{7}{ }^{2-}$ and increase in the extent of protonation of the amino groups. The decrease in the adsorption capacity at higher $\mathrm{pH}$ was attributed to the decrease in the extent of protonation of the amino groups on the silica gel and strong competition between $\mathrm{OH}^{-}$and $\mathrm{CrO}_{4}{ }^{2-}$ ions. This indicated that the electrostatic interaction and ion exchange played important roles in the adsorption of $\mathrm{Cr}(\mathrm{vI})$ (Fig. 4). ${ }^{50}$

\section{Effect of the amount of adsorbent}

The amount of adsorbent is an important key in the process of adsorption. The effect of the dosage amount was investigated by adding different amounts of adsorbents (5 10, 15, and $20 \mathrm{mg})$ in $10 \mathrm{~mL}$ of $\mathrm{Cr}$ (vi) solution (40 ppm for SG-APTES and SG-AEMH, while $20 \mathrm{ppm}$ for MS-APTES and MS-PEI) at $\mathrm{pH}$ 4. Increase in $\mathrm{Cr}(\mathrm{vI})$ adsorption capacity was observed by increasing the amount of adsorbents. SG-AEMH and MS-PEI showed higher adsorption than SG-APTES and MS-APTES (Fig. 5).

Maximum adsorption was achieved at $20 \mathrm{mg}$ for SG-AEMH (98\%) and at $10 \mathrm{mg}$ for MS-PEI (98\%). This could be attributed to the increase in the adsorbent specific surface area and availability of more adsorption sites. ${ }^{63}$

\section{Effect of contact time}

Adsorbent needs to show rapid uptake of pollutants for an ideal and practical adsorption process. To investigate the adsorption capacity of silica sorbents as a function of time, different adsorbents $(10 \mathrm{mg}$ ) developed in this study were added in $10 \mathrm{~mL}$
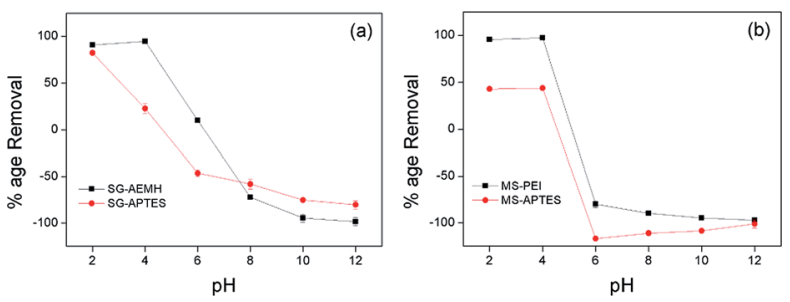

Fig. 4 Effect of $\mathrm{pH}$ on the adsorption of $\mathrm{Cr}(\mathrm{VI})$ by (a) SG-AEMH, SGAPTES, (b) MS-PEI, MS-APTES.
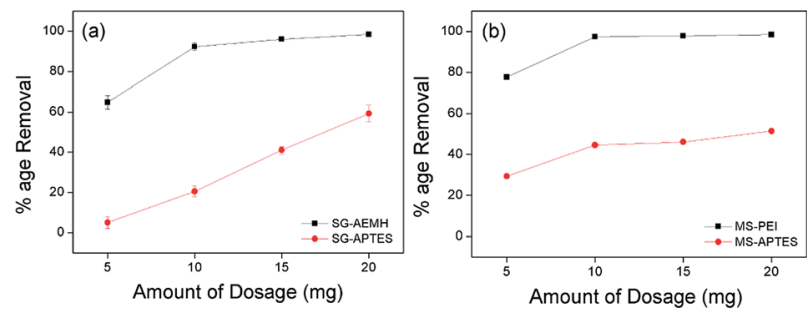

Fig. 5 Effect of amount of dosage on the adsorption of $\mathrm{Cr}(\mathrm{VI})$ by (a) SG-AEMH, SG-APTES, (b) MS-PEI, MS-APTES.

of $\mathrm{Cr}(\mathrm{vI})$ solution (40 ppm for SG-APTES and SG-AEMH, while 20 ppm for MS-APTES and MS-PEI) separately and percentage removal was monitored at room temperature at 5 minutes time intervals for 30 minutes. The uptake of adsorbate increased with contact time. SG-AEMH and MS-PEI showed higher adsorption capacities at any time slot than SG-APTES and MSAPTES. All adsorbents under study exhibited maximum adsorption after $30 \mathrm{~min}$ and thereafter no significant change in removal was observed. Adsorption was 93\% for SG-AEMH and $21 \%$ for SG-APTES while 98\% adsorption was achieved for MSPEI and $44 \%$ for MS-APTES. The rapid adsorption performance of adsorbents might be related to the availability of greater number of active sites in beginning but as the time increases, active surfaces become saturated with adsorbate species. It was rational to assume that the fast adsorption equilibrium was not only due to strong chelation and good affinity of the sorbents towards $\mathrm{Cr}(\mathrm{vI})$ (Fig. 6). ${ }^{64}$

\section{Effect of initial $\mathrm{Cr}(\mathrm{vI})$ concentration}

To investigate the effect of initial concentration on the metal removal capability of adsorbents, adsorption was carried out at different initial concentrations $\left(20,40,60,80,100 \mathrm{mg} \mathrm{L}^{-1}\right)$ with $10 \mathrm{mg}$ of adsorbents. It was observed for all the adsorbents that an increase in $\mathrm{Cr}(\mathrm{vI})$ concentration resulted in the decrease in $\mathrm{Cr}$ (vi) removal capacity (Fig. 7). This trend may be attributed to the lesser number of available active sites for the adsorption against increased $\mathrm{Cr}(\mathrm{vI})$ concentration. ${ }^{65}$

\section{Effect of temperature}

Temperature plays an important role in the process of adsorption. To study the effect of temperature on the adsorption capacity, adsorption was performed at different temperatures
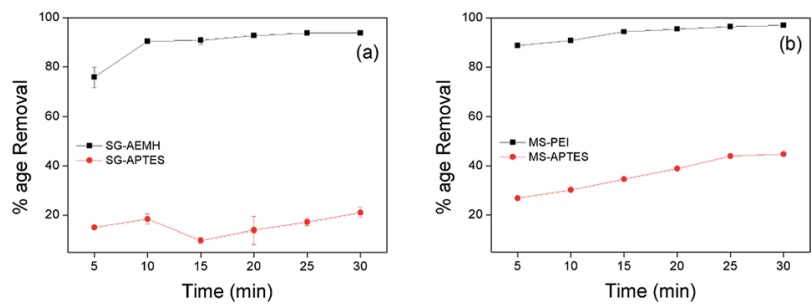

Fig. 6 Effect of contact time on the adsorption of $\mathrm{Cr}(\mathrm{vl})$ by (a) SGAEMH, SG-APTES, (b) MS-PEI, MS-APTES. 

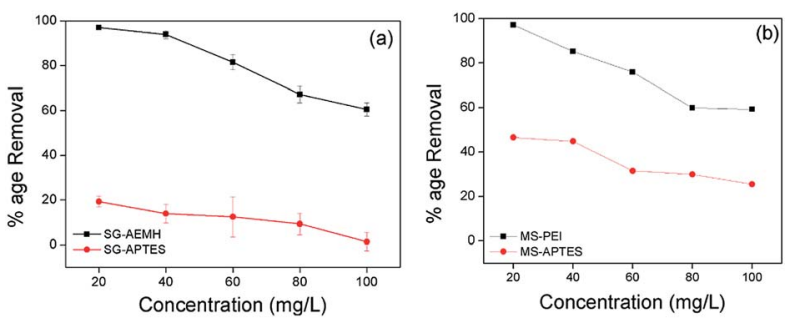

Fig. 7 Effect of initial concentration of $\mathrm{Cr}(\mathrm{VI})$ on the adsorption by (a) SG-AEMH, SG-APTES, (b) MS-PEI, MS-APTES.
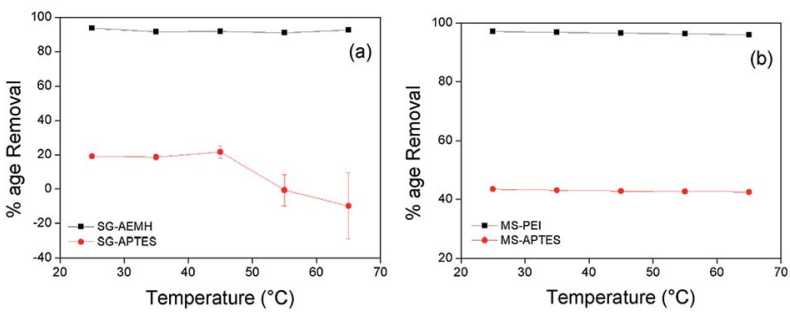

Fig. 8 Effect of temperature on the adsorption of $\mathrm{Cr}(\mathrm{vI})$ by (a) SGAEMH, SG-APTES, (b) MS-PEI, MS-APTES.

$\left(25,35,45,65^{\circ} \mathrm{C}\right) .10 \mathrm{mg}$ of adsorbents were added into $10 \mathrm{~mL}$ chromium metal solution (40 ppm for SG-APTES and SG-AEMH, while $20 \mathrm{ppm}$ for MS-APTES and MS-PEI) and stirred for $30 \mathrm{~min}$ at $\mathrm{pH}$ 4. For all the adsorbents, the adsorption capacity decreased with an increase in temperature. This was attributed to the fact that with increase in temperature the interaction between the metal ions and adsorbents became weak. The highest percentage removal (93\% for SG-AEMH and $98 \%$ for MS-PEI while $21 \%$ for SG-APTES and $44 \%$ for MS-APTES) was observed at room temperature (Fig. 8). ${ }^{66}$

\section{Adsorption isotherms}

The adsorption isotherm facilitates in understanding the relationship between the adsorbate and adsorbent. Langmuir, ${ }^{67}$ Freundlich ${ }^{68}$ isotherms were employed to express the adsorption data. The Langmuir isotherm assumes the monolayer adsorption of metal ions on the homogeneous adsorbent surface with a finite number of adsorption sites and is expressed by the following equation.

$$
\frac{C_{\mathrm{e}}}{q_{\mathrm{e}}}=\frac{1}{q_{\max } b}+\frac{C_{\mathrm{e}}}{q_{\mathrm{max}}}
$$

where $q_{\mathrm{e}}$ is the amount of adsorbed metals ions in the sorbent $\left(\mathrm{mg} \mathrm{g}^{-1}\right), C_{\mathrm{e}}$ is the equilibrium metal ion concentration in solution $\left(\mathrm{mg} \mathrm{L}^{-1}\right), b\left(\mathrm{~L} \mathrm{mg}^{-1}\right)$ is the equilibrium constant related to the adsorption energy, and $q_{\max }$ is the maximum adsorption capacity $\left(\mathrm{mg} \mathrm{\textrm {g } ^ { - 1 }}\right)$. In addition, the viability of adsorption of $\mathrm{Cr}(\mathrm{vI})$ can be expressed by using a dimensionless factor, called separation factor $\left(R_{\mathrm{L}}\right)$, which may be defined by following equation:

$$
R_{\mathrm{L}}=\frac{1}{b C_{0}+1}
$$

where $b$ is the Langmuir constant $\left(\mathrm{L} \mathrm{mg}^{-1}\right)$ and $C_{0}$ refers to the initial metal ions concentration $\left(\mathrm{mg} \mathrm{L}^{-1}\right)$. The value of $R_{\mathrm{L}}$ related to the shape of isotherm indicates whether the adsorption is irreversible $\left(R_{\mathrm{L}}=0\right)$, linear $\left(R_{\mathrm{L}}=1\right)$ favourable $\left(0<R_{\mathrm{L}}<1\right)$ or unfavourable $\left(R_{\mathrm{L}}>1\right)$.

The Freundlich isotherm is based on the assumption that the adsorbate adsorbs onto the heterogeneous adsorbent surface and is not restricted to monolayer formation. The linear form of the Freundlich isotherm is represented by the following equation:

$$
\log q_{\mathrm{e}}=\log K_{\mathrm{F}}+\frac{1}{n} \log C_{\mathrm{e}}
$$

where $K_{\mathrm{F}}$ is the Freundlich isotherm constant related to adsorption capacity. $C_{\mathrm{e}}$ and $q_{\mathrm{e}}$ are the equilibrium concentration of adsorbate in solution and on adsorbent respectively. The slope $1 / n$ (with favorable range between 0 and 1 ) is the measure of surface heterogeneity and adsorption intensity, respectively. The lower the value of $1 / n$, the more heterogeneous is the adsorption process. Table 1 summarizes both the Langmuir and the Freundlich parameters, together with the correlation coefficients.

Table 2 summarizes both the Langmuir and the Freundlich parameters, together with the correlation coefficients. It can be observed that for SG-AEMH the Langmuir model provided a good fit to the experimental data with high $R^{2}(0.99)$ value compared to the Freundlich model $R^{2}(0.87)$

In case of MS-PEI, the value of $R^{2}$ for the Freundlich isotherm model (0.98) was slightly higher than that for the Langmuir (0.97). Furthermore, the higher values of $b$ (Langmuir constant) for SG-AEMA $\left(0.31 \mathrm{~L} \mathrm{mg}^{-1}\right)$ and MS-PEI $(0.60 \mathrm{~L}$ $\mathrm{mg}^{-1}$ ) indicated a stronger attraction of $\mathrm{Cr}(\mathrm{VI})$ ions on the polymer functionalized surfaces compared to the monolayer based adsorbent surfaces. The maximum adsorption capacities $\left(q_{\text {max }}\right)$ for SG-AEMH (63.29) and MS-PEI (50.26) are higher than SG-APTES (10.34) and MS-APTES (34.09). The calculated values of $1 / n$ range between 0 and 1 for all adsorbents imply that adsorption process was chemical in nature. The values of $1 / n$ depict adsorption process is more heterogeneous for MSPEI (0.23) than for SG-AEMH (0.30). Moreover, the calculated

\begin{tabular}{|c|c|c|c|c|c|}
\hline & Parameters & SG-APTES & SG-AEMH & MS-APTES & MS-PEI \\
\hline \multirow[t]{7}{*}{ Langmuir } & \multirow{2}{*}{$q_{\max }(\mathrm{mg} / \mathrm{g})$} & 10.34 & 63.29 & 34.09 & 50.26 \\
\hline & & \pm 2.26 & \pm 2.12 & \pm 1.15 & \pm 1.11 \\
\hline & \multirow[t]{2}{*}{$b\left(\mathrm{~L} \mathrm{mg}^{-1}\right)$} & 0.15 & 0.31 & 0.56 & 0.60 \\
\hline & & \pm 0.05 & \pm 0.01 & \pm 0.01 & \pm 0.02 \\
\hline & \multirow[t]{2}{*}{$R_{\mathrm{L}}$} & 0.24 & 0.13 & 0.57 & 0.07 \\
\hline & & \pm 0.03 & \pm 0.02 & \pm 0.02 & \pm 0.01 \\
\hline & $R^{2}$ & 0.88 & 0.99 & 0.94 & 0.97 \\
\hline \multirow[t]{5}{*}{ Freundlich } & \multirow[t]{2}{*}{$K_{\mathrm{F}}\left(\mathrm{mg} \mathrm{g}^{-1}\right)$} & 2.61 & 20.92 & 2.80 & 22.67 \\
\hline & & 1.26 & \pm 1.50 & \pm 1.52 & \pm 1.31 \\
\hline & \multirow[t]{2}{*}{$1 / n$} & 0.32 & 0.30 & 0.54 & 0.23 \\
\hline & & \pm 0.15 & \pm 0.01 & \pm 0.01 & \pm 0.01 \\
\hline & $R^{2}$ & 0.31 & 0.87 & 0.86 & 0.98 \\
\hline
\end{tabular}

Table 2 Langmuir and Freundlich isotherm parameters for the adsorption of $\mathrm{Cr}(\mathrm{vl})$ 
Table 3 Kinetic parameters for the adsorption of $\mathrm{Cr}(\mathrm{vI})$ ions

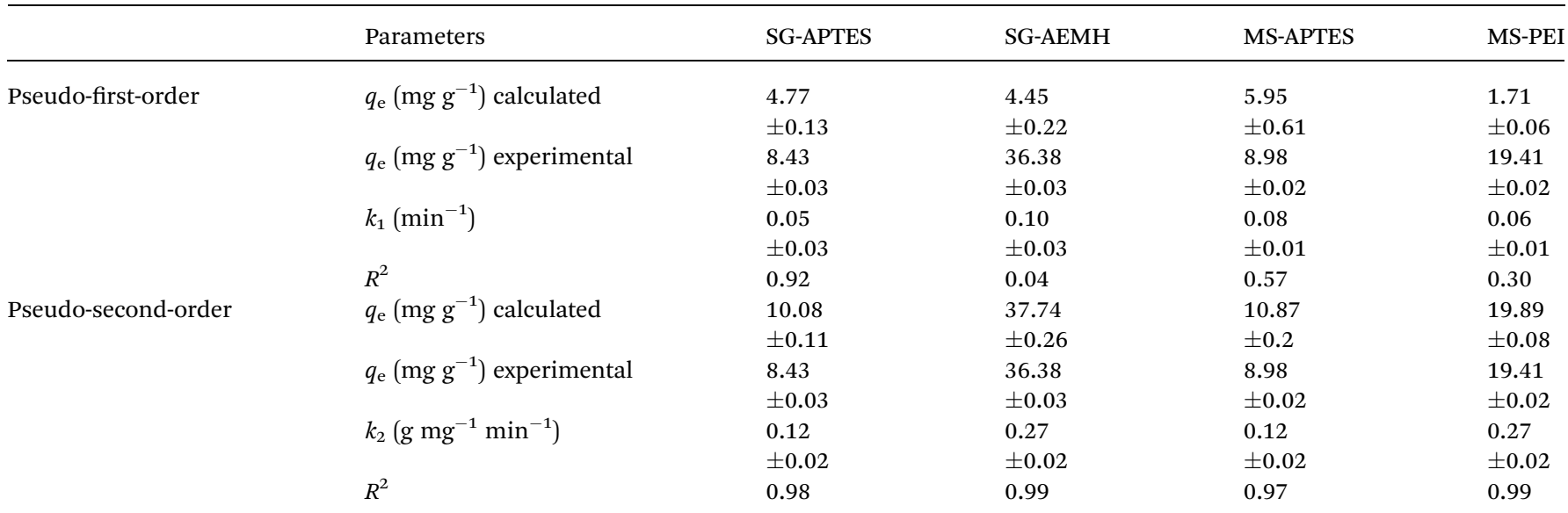

value of $R_{\mathrm{L}}$ is also in the required range of $0<R_{\mathrm{L}}<1$ for SGAEMH (0.13) and MS-PEI (0.07), signifying a favourable adsorption of $\mathrm{Cr}(\mathrm{VI}){ }^{49,69-71}$

\section{Adsorption kinetics}

Adsorption kinetic is one of the most important parameter, which represents the adsorption efficiency. It determines the adsorbate uptake rate and evaluates the equilibrium time required for the sorption isotherm. To understand the kinetic mechanism of the adsorption process, pseudo-first-order ${ }^{72}$ and pseudo-second-order ${ }^{73}$ kinetics models were applied to fit the kinetic data. The linear form of pseudo-first-order kinetic equation is expressed by following equation:

$$
\log \left(q_{\mathrm{e}}-q_{t}\right)=\log q_{\mathrm{e}}-\left(\frac{k_{1}}{2.303}\right) t
$$

where $q_{\mathrm{e}}$ and $q_{t}$ are the amount of metal ions adsorbed on the adsorbent in $\mathrm{mg} \mathrm{g}^{-1}$ at equilibrium and at time $t$, respectively, and $k_{1}$ is the constant of first-order adsorption $\left(\mathrm{min}^{-1}\right)$.

The pseudo-second-order kinetic rate equation is linearly expressed as following:

$$
\frac{t}{q_{t}}=\frac{1}{k_{2} q_{\mathrm{e}}^{2}}+\frac{1}{q_{\mathrm{e}}} t
$$

where $k_{2}$ is the pseudo-second-order rate constant at the equilibrium ( $\mathrm{g} \mathrm{mg}^{-1} \mathrm{~min}^{-1}$ ) that can be determined experimentally. The kinetics parameters and correlation coefficients were calculated from the linear plots and are listed in Table 3. The adsorption data of SG-APTES, MS-APTES, SG-AEMH and MS-PEI fit the pseudo-second-order model with higher correlation coefficient $\left(R^{2}\right)$ values. The theoretical $q_{\mathrm{e}}$ values for the adsorbents were very close to the experimental $q_{\mathrm{e}}$ values in the case of second-order kinetics. These results suggest that the rate limiting step involves chemisorption of the adsorbate onto the adsorbent. ${ }^{74-77}$

\section{Adsorption thermodynamics}

To evaluate the thermodynamic feasibility and spontaneous nature of the adsorption process, thermodynamic parameters including the entropy $\left(\Delta S^{\circ}\right)$, enthalpy $\left(\Delta H^{\circ}\right)$ and standard Gibbs free energy $\left(\Delta G^{\circ}\right)$ were calculated. ${ }^{78-80}$

The magnitude of $\Delta G^{\circ}$ was calculated from the following equation:

$$
\Delta G^{\circ}=-R T \ln K
$$

Where $K$ is the equilibrium constant, $T$ is the absolute temperature $(\mathrm{K})$, and $R$ is the universal gas constant $(8.314 \mathrm{~J}$ $\left.\mathrm{mol}^{-1} \mathrm{~K}^{-1}\right)$.

The change in enthalpy $\Delta H^{\circ}$ and $\Delta S^{\circ}$ can be determined from the following equation:

$$
\ln K=\frac{\Delta S^{\circ}}{R}-\frac{\Delta H^{\circ}}{R T}
$$

The equilibrium constant $K$ can be calculated as expressed in eqn (9):

$$
K=\frac{q_{\mathrm{e}}}{C_{\mathrm{e}}}
$$

where, $K$ is the equilibrium constant, $q_{\mathrm{e}}$ is the solid phase concentration at equilibrium $\left(\mathrm{mg} \mathrm{L}^{-1}\right)$ and $C_{\mathrm{e}}$ is the equilibrium concentration in solution $\left(\mathrm{mg} \mathrm{L}^{-1}\right)$.

The values of the thermodynamic parameters are given in Table 4 . The negative values of $\Delta G^{\circ}$ implied that the adsorption process was feasible and spontaneous.

In addition, the negative values of $\Delta H^{\circ}$ suggested that the adsorption of Cr(vI) onto SG-AEMH, SG-APTES, MS-PEI and MSAPTES was exothermic in nature.

The positive values of $\Delta S^{\circ}$ for SG-AEMH and MS-PEI exhibited the increasing randomness at the solid-liquid interfaces during the adsorption of metal ions on the adsorbents and could be due to some structural changes in the adsorbents. While, the negative values of $\Delta S^{\circ}$ for SG-APTES and MS-APTES suggested that the randomness decreased at the solid/ solution interface as a results of $\mathrm{Cr}(\mathrm{vI})$ adsorption onto the surface of adsorbents. This implied that the adsorption process was energetically stable. ${ }^{\mathbf{8 1 - 8 4}}$

The molar entropy of adsorption is 
Table 4 Thermodynamic parameters for the adsorption of $\mathrm{Cr}(\mathrm{VI})$ ions

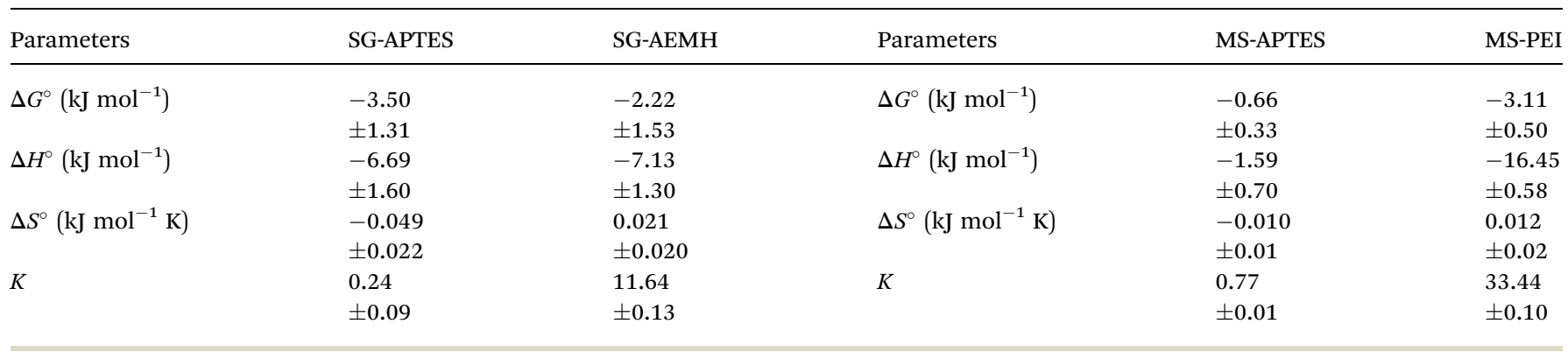

$$
\Delta_{\mathrm{ad}} S_{m}=S_{m}{ }^{\sigma}-S_{m}^{1}
$$

where ad is adsorption, $m$ is molar, $\sigma$ is interface, and 1 is solution phase (liquid).

While $S_{m}{ }^{\sigma}$ can be calculated from following equation:

$$
S_{m}{ }^{\sigma}=\frac{\mathrm{d} S^{\sigma}}{\mathrm{d} N^{\sigma}} \mid T, A
$$

where $N^{\sigma}$ is moles of adsorbate at the interface, $T$ is temperature and $A$ is the total area of the adsorbent.

For monolayer based surfaces (SG-APTES and MS-APTES), $\Delta S_{m}$ is negative (the entropy of adsorbates at the interface is smaller than the entropy in the solution). Therefore, entropically driven adsorption is restricted. This is because, the entropy of molecules on the monolayer coated surface is much lower than in solution phase since vibrational, rotational and also translational degrees of freedom are restricted at the interface. However, the polymer decorated silica gel (SG-AEMH) and mesoporous silica (MS-PEI) showed positive entropy change upon adsorption, since molecules have more freedom to move compared to monolayer. Besides, the positive value of entropy also means that the change of amount of adsorbate as a function of entropy at the interface is larger than in the solution. Therefore, entropy driven adsorption is more favorable for polymer functionalized solid adsorbents as compared to their monolayer counterparts.

\section{Desorption}

A successful desorption process must restore the adsorbent close to its initial properties for effective reutilization. Sorbent regeneration is significant in evaluating the competitiveness of the adsorbent system. The regeneration of adsorbents was
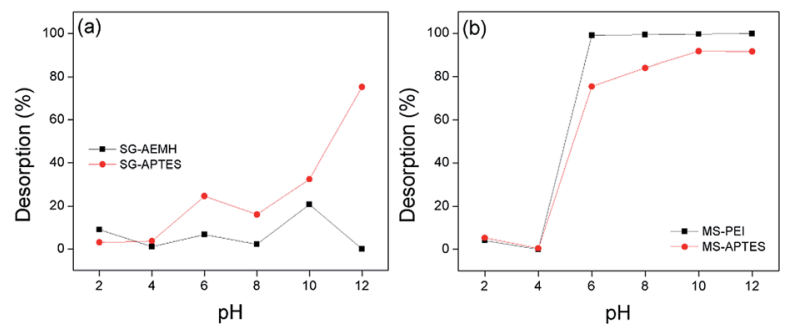

Fig. 9 Effect of $\mathrm{pH}$ on desorption from (a) SG-APTES and SG-AEMH (b) MS-APTES and MS-PEI.
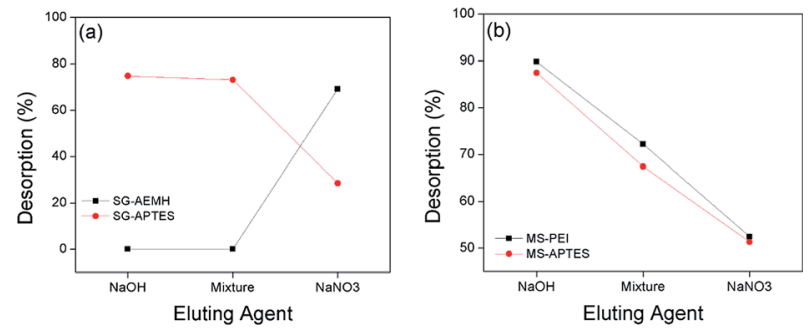

Fig. 10 Effect of eluting agents on desorption from (a) SG-APTES and SG-AEMH (b) MS-APTES and MS-PEI.

monitored by different eluting agents $\left(\mathrm{NaOH}, \mathrm{NaNO}_{3}\right.$, mixture of $\left.\mathrm{NaOH}_{\text {with }} \mathrm{NaNO}_{3}(1: 1)\right)$. It was observed that best desorption results for SG-AEMH (up to 70\%) were obtained by using $\mathrm{NaNO}_{3}$ and for SG-APTES (up to 74\%) were obtained by using $\mathrm{NaOH}$, while for MS-PEI (up to $90 \%$ ) and MS-APTES (up to 88\%) the best desorption results were obtained by using $\mathrm{NaOH}$. The effect of $\mathrm{pH}$ on desorption was also explored. The maximum desorption was observed at basic conditions, due to an increase in the negative species in the media (Fig. 9).

At higher $\mathrm{pH}(\mathrm{pH}=10)$, desorption was up to $20 \%$ for SGAEMH, whereas desorption percentage was up to $75 \%$ in the case of SG-APTES at $\mathrm{pH}=12$, while, desorption was up to $98 \%$ for MS-PEI and up to $91 \%$ in the case of MS-APTES at $\mathrm{pH}=12$ (Fig. 10). ${ }^{85,86}$

\section{Regeneration/reusability}

The regeneration ability of the adsorbent reduces the process cost and assesses the competence of adsorption systems. To investigate the reusability, $\mathrm{Cr}(\mathrm{vI})$ loaded adsorbents were
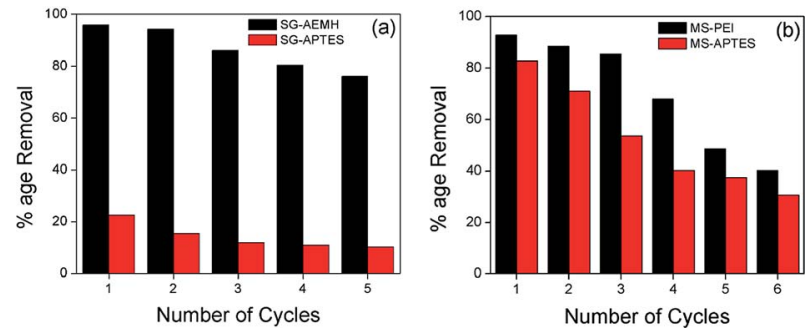

Fig. 11 Reusability of (a) SG-APTES and SG-AEMH, (b) MS-APTES and MS-PEI. 
washed with $0.1 \mathrm{M} \mathrm{NaOH}$ solution and then rinse with deionized water to neutrality and reconditioned for reuse. The results showed that a performance drop of $21 \%$ and $57 \%$ was observed in the adsorption capacity of SG-AEMH and SG-APTES between the 1st and 5th cycles, respectively. MS-PEI could be effectively reused up to sixth adsorption-desorption cycles with 56\% performance loss while, a drop of $63 \%$ was observed in the adsorption capacity of MS-APTES up to sixth cycle (Fig. 11). ${ }^{87,88}$

\section{Conclusions}

In summary, silica gel was functionalized with polymer to improve the adsorption behaviour towards $\operatorname{Cr}(\mathrm{vI})$. The removal efficiency of polymer functionalized silica (SG-AEMH) was compared with the mesoporous silica tethered with a branched polymer (MS-PEI). The polymer decorated silica gel (SG-AEMH) and mesoporous silica (MS-PEI) exhibited better adsorption capacities as compared to the monolayer based SG-APTES and MS-APTES platforms. The prepared silica sorbents exhibited attractive characteristics, such as high adsorption capacity, fast adsorption kinetics, and superior regeneration performance. The adsorption process of SG-AEMH was well described with a Langmuir model while Freundlich model gave a good fit for the adsorption data of MS-PEI. Pseudo-second order equation gave a better correlation for the adsorption data of SG-AEMH and MS-PEI. The thermodynamic study indicated that the adsorption processes were spontaneous and exothermic for SGAEMH and MS-PEI based sorbents. The present study revealed that SG-AEMH and MS-PEI are promising materials for the removal of $\mathrm{Cr}(\mathrm{vI})$ ions from aqueous media and could be regenerated and reused up to five cycles for SG-AEMH and six cycles for MS-PEI that highlight their economic viability.

\section{Conflicts of interest}

There are no conflicts to declare.

\section{Acknowledgements}

B. Y. acknowledges The Higher Education Commission (HEC) of Pakistan for Funding (NRPU Project No. 20-1740/R\&D/10/ 3368, 20-1799/R\&D/10-5302 and 5922), Human Frontier Science Program (HFSP), and LUMS for the Startup Grant. H. D. gratefully acknowledges The Scientific and Technological Research Council of Turkey (TUBITAK) for the financial support of Project No. 112M804.

\section{Notes and references}

1 J. K. Bediako, W. Wei, S. Kim and Y.-S. Yun, J. Hazard. Mater., 2015, 299, 550-561.

2 X. Wang, Y. Pei, M. Lu, X. Lu and X. Du, J. Mater. Sci., 2015, 50, 2113-2121.

3 H. A. Hegazi, HBRC Journal, 2013, 9, 276-282.

4 J. Zhou, Y. Wang, J. Wang, W. Qiao, D. Long and L. Ling, J. Colloid Interface Sci., 2016, 462, 200-207.
5 M. Hua, S. Zhang, B. Pan, W. Zhang, L. Lv and Q. Zhang, J. Hazard. Mater., 2012, 211, 317-331.

6 D.-P. Sui, H.-X. Chen, L. Liu, M.-X. Liu, C.-C. Huang and H.-T. Fan, Talanta, 2016, 148, 285-291.

7 S. Li, F. Qi, M. Xiao, H. Fan, Y. Shen, K. Du, Z. Zhang and W. Li, Water Sci. Technol., 2017, 75, 1466-1473.

8 H.-T. Fan, Z.-J. Su, X.-L. Fan, M.-M. Guo, J. Wang, S. Gao and T. Sun, J. Sol-Gel Sci. Technol., 2012, 64, 418-426.

9 H. Chen, Y.-Y. Zhang, K.-L. Zhong, L.-W. Guo, J.-L. Gu, L. Bo, M.-H. Zhang and J.-R. Li, J. Hazard. Mater., 2014, 271, 160165.

10 A. Gupta and C. Balomajumder, J. Environ. Chem. Eng., 2015, 3, 785-796.

11 X. Sun, L. Yang, Q. Li, J. Zhao, X. Li, X. Wang and H. Liu, Chem. Eng. J., 2014, 241, 175-183.

12 F. Fu and Q. Wang, J. Environ. Manage., 2011, 92, 407-418. 13 P. Z. Ray and H. J. Shipley, RSC Adv., 2015, 5, 29885-29907. 14 D.-L. Huang, R.-Z. Wang, Y.-G. Liu, G.-M. Zeng, C. Lai, P. Xu, B.-A. Lu, J.-J. Xu, C. Wang and C. Huang, Environ. Sci. Pollut. Res., 2015, 22, 963-977.

15 W. Jinhua, Z. Xiang, Z. Bing, Z. Yafei, Z. Rui, L. Jindun and C. Rongfeng, Desalination, 2010, 259, 22-28.

16 G. Bayramoğlu and M. Yakup Arica, Chem. Eng. J., 2008, 139, 20-28.

17 S. Li, F. Qi, M. Xiao, H. Fan, Y. Shen, K. Du, Z. Zhang and W. Li, Water Sci. Technol., 2017, 75, 1466-1473.

18 L. Li, Y. Li, L. Cao and C. Yang, Carbohydr. Polym., 2015, 125, 206-213.

19 L. Aboutorabi, A. Morsali, E. Tahmasebi and O. Büyükgüngor, Inorg. Chem., 2016, 55, 5507-5513.

20 Z. Dong and L. Zhao, Carbohydr. Polym., 2018, 189, 190-197. 21 R. Wang, X. Shi, H. Wang and C. Lei, J. Chem. Eng. Data, 2015, 60, 1454-1463.

22 O. Gunduz, M. Yetmez, M. Sonmez, M. Georgescu, L. Alexandrescu, A. Ficai, D. Ficai and E. Andronescu, Curr. Top. Med. Chem., 2015, 15, 1501-1515.

23 B. Samiey, C.-H. Cheng and J. Wu, Materials, 2014, 7, 673.

24 H.-T. Fan, Q. Tang, Y. Sun, Z.-G. Zhang and W.-X. Li, Chem. Eng. J., 2014, 258, 146-156.

25 E. Repo, J. K. Warchoł, A. Bhatnagar and M. Sillanpää, J. Colloid Interface Sci., 2011, 358, 261-267.

26 M. K. Dinker and P. S. Kulkarni, J. Chem. Eng. Data, 2015, 60, 2521-2540.

27 H.-T. Fan, Y. Sun, Q. Tang, W.-L. Li and T. Sun, J. Taiwan Inst. Chem. Eng., 2014, 45, 2640-2648.

28 S. Hou, X. Li, H. Wang, M. Wang, Y. Zhang, Y. Chi and Z. Zhao, RSC Adv., 2017, 7, 51993-52000.

29 V. B. Cashin, D. S. Eldridge, A. Yu and D. Zhao, Environ. Sci.: Water Res. Technol., 2018, 4, 110-128.

30 W. Yang, P. Ding, L. Zhou, J. Yu, X. Chen and F. Jiao, Appl. Surf. Sci., 2013, 282, 38-45.

31 B. Akhavan, K. Jarvis and P. Majewski, ACS Appl. Mater. Interfaces, 2015, 7, 4265-4274.

32 H.-T. Fan, X.-T. Sun and W.-X. Li, J. Sol-Gel Sci. Technol., 2014, 72, 144-155. 
33 S. Radi, S. Tighadouini, M. El Massaoudi, M. Bacquet, S. Degoutin, B. Revel and Y. N. Mabkhot, J. Chem. Eng. Data, 2015, 60, 2915-2925.

34 S. Qihui, L. Man, Y. Dongdong, G. Hanliang, L. Yan, L. Xiaoyang and Z. Jianguang, J. Chin. Chem. Soc., 2018, 65, 591-596.

35 F. Hoffmann, M. Cornelius, J. Morell and M. Fröba, Angew. Chem., Int. Ed., 2006, 45, 3216-3251.

36 M. K. Dinker and P. S. Kulkarni, J. Chem. Eng. Data, 2015, 60, 2521-2540.

37 W. J. Hunks and G. A. Ozin, J. Mater. Chem., 2005, 15, 37163724.

38 D. Bruhwiler, Nanoscale, 2010, 2, 887-892.

39 H. Ritter and D. Brühwiler, J. Phys. Chem. C, 2009, 113, 10667-10674.

40 J. Yuan, D. Wan and Z. Yang, J. Phys. Chem. C, 2008, 112, 17156-17160.

41 S. Egodawatte, A. Datt, E. A. Burns and S. C. Larsen, Langmuir, 2015, 31, 7553-7562.

42 A. Imyim, C. Thanacharuphamorn, A. Saithongdee, F. Unob and V. Ruangpornvisuti, Desalin. Water Treat., 2015, 1-10.

43 T. Ogata, H. Narita and M. Tanaka, Hydrometallurgy, 2015, 152, 178-182.

44 R. Karthik and S. Meenakshi, Journal of Water Process Engineering, 2014, 1, 37-45.

45 F. Makavipour and R. M. Pashley, Chem. Eng. J., 2015, 262, 119-124.

46 X. Li, B. Shi, Y. Wang, M. Li, Y. Liu, L. Gao and L. Mao, Microporous Mesoporous Mater., 2015, 214, 15-22.

47 S. Nayab, A. Farrukh, Z. Oluz, E. Tuncel, S. R. Tariq, H. u. Rahman, K. Kirchhoff, H. Duran and B. Yameen, ACS Appl. Mater. Interfaces, 2014, 6, 4408-4417.

48 A. Koenig, U. Ziener, A. Schaz and K. Landfester, Macromol. Chem. Phys., 2007, 208, 155-163.

49 A. Farrukh, A. Akram, A. Ghaffar, S. Hanif, A. Hamid, H. Duran and B. Yameen, ACS Appl. Mater. Interfaces, 2013, 5, 3784-3793.

50 Q. Wu, R. You, Q. Lv, Y. Xu, W. You and Y. Yu, Chem. Eng. J., 2015, 281, 491-501.

51 R. Kumar, M. Ehsan and M. A. Barakat, J. Ind. Eng. Chem., 2014, 20, 4202-4206.

52 S. S. Liu, Y. Z. Chen, L. De Zhang, G. M. Hua, W. Xu, N. Li and Y. Zhang, J. Hazard. Mater., 2011, 190, 723-728.

53 A. Nematollahzadeh, S. Seraj and B. Mirzayi, Chem. Eng. J., 2015, 277, 21-29.

54 E. Mahmoudi and M. A. Behnajady, Colloids Surf., A, 2018, 538, 287-296.

55 N. Li, F. Fu, J. Lu, Z. Ding, B. Tang and J. Pang, Environ. Pollut., 2017, 220, 1376-1385.

56 J. Yu, C. Jiang, Q. Guan, P. Ning, J. Gu, Q. Chen, J. Zhang and R. Miao, Chemosphere, 2018, 195, 632-640.

57 T. K. Vo, H.-K. Park, C.-W. Nam, S.-D. Kim and J. Kim, J. Ind. Eng. Chem., 2018, 60, 485-492.

58 A. V. Bankar, A. R. Kumar and S. S. Zinjarde, J. Hazard. Mater., 2009, 170, 487-494.

59 A. Z. M. Badruddoza, B. Bhattarai and R. P. S. Suri, ACS Sustainable Chem. Eng., 2017, 5, 9223-9232.
60 R. Davarnejad, Z. Karimi Dastnayi and J. F. Kennedy, Int. J. Biol. Macromol., 2018, 116, 281-288.

61 L.-L. Li, X.-Q. Feng, R.-P. Han, S.-Q. Zang and G. Yang, J. Hazard. Mater., 2017, 321, 622-628.

62 M. K. Dinker and P. S. Kulkarni, New J. Chem., 2015, 39, 3687-3697.

63 R. Karthik and S. Meenakshi, Journal of Water Process Engineering, 2014, 1, 37-45.

64 M. Anbia, K. Kargosha and S. Khoshbooei, Chem. Eng. Res. Des., 2015, 93, 779-788.

65 V. Kumari, M. Sasidharan and A. Bhaumik, Dalton Trans., 2015, 44, 1924-1932.

66 M. H. Dindar, M. R. Yaftian and S. Rostamnia, J. Environ. Chem. Eng., 2015, 3, 986-995.

67 I. Langmuir, J. Am. Chem. Soc., 1918, 40, 1361-1403.

68 H. Freundlich, Z. Phys. Chem., 1907, 57, 385-470.

69 Y. Wu, J. Zhou, Y. Jin, J. Cao, P. Yilihan, Y. Wen and Y. Wu, Environ. Sci. Pollut. Res., 2014, 21, 1859-1874.

70 J. Pizarro, X. Castillo, S. Jara, C. Ortiz, P. Navarro, H. Cid, H. Rioseco, D. Barros and N. Belzile, Fuel, 2015, 156, 96-102.

71 L.-C. Lin, M. Thirumavalavan and J.-F. Lee, Clean: Soil, Air, Water, 2015, 43, 775-785.

72 S. K. Lagergren and S. Vetenskapsakad, Handingarl, 1898, 24, 1-39.

73 Y. S. Ho and G. McKay, Process Biochem., 1999, 34, 451-465. 74 P. Wang, M. Du, H. Zhu, S. Bao, T. Yang and M. Zou, J. Hazard. Mater., 2015, 286, 533-544.

75 S. E. Gomez-Gonzalez, G. G. Carbajal-Arizaga, R. ManriquezGonzalez, W. De la Cruz-Hernandez and S. Gomez-Salazar, Mater. Res. Bull., 2014, 59, 394-404.

76 S. Hozhabr Araghi and M. H. Entezari, Appl. Surf. Sci., 2015, 333, 68-77.

77 Y. Ding, W. Zhu, Y. Xu and X. Qian, Sens. Actuators, B, 2015, 220, 762-771.

78 M. Akram, H. N. Bhatti, M. Iqbal, S. Noreen and S. Sadaf, J. Environ. Chem. Eng., 2017, 5, 400-411.

79 A. Alizadeh, G. Abdi, M. M. Khodaei, M. Ashokkumar and J. Amirian, RSC Adv., 2017, 7, 14876-14887.

80 X. Jiang, H. Luo, Y. Yin and W. Zhou, RSC Adv., 2017, 7, 24149-24156.

81 S. S. Thakur and G. S. Chauhan, Ind. Eng. Chem. Res., 2014, 53, 4838-4849.

82 T. A. Saleh, Desalin. Water Treat., 2015, 1-15.

83 M. Maretto, R. Vignola, C. D. Williams, R. Bagatin, A. Latini and M. Petrangeli Papini, Microporous Mesoporous Mater., 2015, 203, 139-150.

84 M. Tahergorabi, A. Esrafili, M. Kermani and M. ShirzadSiboni, Desalin. Water Treat., 2015, 1-12.

85 D. Kong, F. Zhang, K. Wang, Z. Ren and W. Zhang, Ind. Eng. Chem. Res., 2014, 53, 4434-4441.

86 S. P. Bayen and P. Chowdhury, Desalin. Water Treat., 2014, 52, 1550-1559.

87 L. Tang, Y. Fang, Y. Pang, G. Zeng, J. Wang, Y. Zhou, Y. Deng, G. Yang, Y. Cai and J. Chen, Chem. Eng. J., 2014, 254, 302312.

88 S. Wang, K. Wang, C. Dai, H. Shi and J. Li, Chem. Eng. J., 2015, 262, 897-903. 